\title{
XVIII. On symbolic notation, as applied to mineralogy
}

\author{
H.J. Brooke Esq. F.R.S. F.L.S. F.G.S.
}

To cite this article: H.J. Brooke Esq. F.R.S. F.L.S. F.G.S. (1836) XVIII. On symbolic notation, as applied to mineralogy , Philosophical Magazine Series 3, 8:45, 101-103, DOI:

10.1080/14786443608648814

To link to this article: http://dx.doi.org/10.1080/14786443608648814

央 Published online: 01 Jun 2009.

Submit your article to this journal $\sqsubset \pi$

Q View related articles $\longleftarrow$ 


\section{[ 101 ]}

XVIII. On Symbolic Notation, as applied to Mineralogy. By H. J. Brooke, Esq., F.R.S. F.L.S. F.G.S.

Dear Sir,

To Richard Phillips, Esq.

THAVE, at the repeated solicitation of several of my friends, undertaken and made some progress in a new work on Mineralogy, in the course of which some difficulties have occurred relative to the cbemical constitution of minerals and their distribution into species, which perhaps some of your chemical readers may assist in removing; and on this account I shall feel obliged by an early insertion of this notice in your Journal.

Before I commenced the work in which I am engaged, I had thought of proposing a new edition of the late W. Phillips's useful volume; but upon a close examination of its contents I found it would require so much correction, and so great a remodelling, to adapt it to the present state of mineralogical knowledge, that it would be less troublesome to prepare a new treatise.

Notwithstanding the decided objection entertained by you to the use of symbols, I am disposed to regard them as very serviceable in oconomizing time and labour; and it will probably turn out that your objection applies rather to the unnecessary and capricious changes to which these short-hand characters have been subjected, and their employment in the expression of conflicting theories, than to the characters themselves.

Symbols were first introduced by Berzelius, which fully answered the purpose for which they were intended; and it would have been much better, and much confusion would have been spared, if they had been rigidly adhered to, notwithstanding any slight improvement of which they might have been susceptible. But, unfortunately, in the symbolical representations of the composition of minerals published by different authors, not only are the symbols of Berzelius changed, but the formulæ are made up according to the peculiar views of each author concerning atomic weights, and their several notions of the most fit manner of parcelling out into definite compounds such of those constituents of a mineral, as given by analysis, as they choose to consider essential to its constitution, after having rejected whatever they imagine to be foreign matter.

These differences will be apparent on a comparison of the analyses of different minerals, as given by Leonhard in his Handbuch der Oryctognosie, and by Thomson in his recently 
published work on Mineralogy, with the formulæ by which the composition of such minerals is expressed.

Hence arises the difficulty in selecting a chemical formula which shall accurately represent the chemical constitution of a mineral, and particularly as other symbolical expressions might, with a little contrivance, be framed to represent equally well the result of the same analysis. A question, therefore, occurs whether there is any rule to guide us in determining which formula is the most correct.

The doctrine of definite proportions is, as I understand it, applicable to all cases of chemical union. An electro-positive and an electro-negative element are, in all cases, to be regarded as the combining atoms, whether such elements are simple, or consist of binary, quaternary, or any other compound of simple elements. Thus, one proportional of oxalic acid and one of potash are the combining atoms in oxalate of potash ; in binoxalate, two proportionals of the acid form the atom; and in quadroxalate four proportionals. But in what manner do these two and four proportionals constitute the combining atoms? Again, in sulphate of nickel and potash, are the two elements sulphates; or is sulphuric acid one, and the combined oxides the other? And what function does the water perform in hydrous salts, as it does not appear in the formulæ representing such? in what manner, or even whether it is combined with any, or which, of the elements of the compound in which it occurs?

On referring, however, to the last edition of Berzelius's Theory of Chemical Proportions, I find that the inquiry I have thus ventured to suggest will probably not produce a satisfactory answer; but as some chemists retain in their formulæ, and others reject, the same ingredient of a mineral, as shown by analysis, they perhaps have some rule by which they are guided, and which if worked out might furnish a clue to the object I am seeking. 'The passage from Berzelius is as follows: "Sulphuric acid, potash, alumina, and water are compound atoms of the frst order; sulphate of potash and sulphate of alumina are of the second order; dry [anhydrous] alum, of the third order; and lastly, crystallized alum, containing water combined with the double sulphate, may be regarded as an atom of the fourth order. We are as yet ignorant of the extent of the number of these orders. Affinity among compound atoms decreases rapidly as the numbers of the orders increase; and the degree which exists even among atoms of the third order is too feeble to be observed in the operations of the laboratory. This affinity is seldom manifested, except in minerals; and to understand thoroughly the nature of these, it is necessary to know how far the combination of compound atoms can take place, 
and whether there is any limit to the numbers of the orders of the combining atoms."

Under these circumstances, it would have been better not to construct any mineralogical formulæ, except the simple ones; and in future the composition of such minerals as involve the uncertain orders of atoms should be expressed simply by the proportion of each ingredient in 1000th parts, or by the nearest equivalent numbers of each, taking the element which occurs in the smallest quantity as an atomic unit. We should then express by our formulæ what we know, instead of contriving to represent an imaginary atomic constitution, which, if the atomic theory be true, is probably in all cases false.

January 7 th, 1836.

I am, dear Sir, yours truly,

H. J. Brooke.

XIX. On the Laws of Reflexion from crystallized Surfaces. By J. MacCullagh, Fellow of Trinity College, Dublin.

Dear Sir,

\section{To Sir David Brerwster.}

I HAVE great pleasure in sending you an account of the 1 laws by which I conceive that the vibrations of light are regulated when a ray is reflected and refracted at the separating surface of two media; especially as the only guide which I had, in my inquiry after these laws, was your paper on the action of crystallized surfaces upon light, published in the Philosophical Transactions for the year 1819. The observation which I found there, that the polarizing angle was the same for a given plane of incidence, "whether the obtuse angle of the rhomb [of Iceland spar] was nearest or furthest from the eye, or whether it was to the right or left hand of the observer," disappointed me at first, being contrary to what I had anticipated from principles analogous to those which had been employed by Fresnel in the problem of reflexion from ordinary media. I then sought other principles, and the observation is now a result of theory.

Assuming, as a basis for calculation, that Fresnel's law of double refraction is rigorously true, I have been obliged to make an essential change in his physical ideas. Conceive an ellipsoid whose semiaxes are parallel to the three principal directions of the crystal, and equal respectively to its three principal indices of refraction, and let a central section of the ellipsoid be made by a plane parallel to the plane of a wave passing through the crystal. The section will be an ellipse, and the wave will be polarized by the crystal in a plane pa- 